\title{
Respuesta al comentario del Dr. Aquero
}

\section{Alberto M. L. CALDEIRA}

Desde el inicio de mi carrera, tengo establecido que la continua búsqueda de la excelencia debe situarse como principio fundamental de nuestra actividad. Siguiendo mi natural y verdadera vocación por la enseñanza, quiero decirles que el privilegio de trabajar con jóvenes talentosos cirujanos siempre me exigió buscar la persistente actualización de mis conocimientos para encarar de forma responsable y consecuente los desafíos de las grandes deformidades o de aquellas que parecían incorregibles.

Me gustaría esclarecer algunos puntos sobre cada uno de los 3 casos presentados y que fueron comentados por el Dr. Pedro Arquero.

El primer caso es el de una paciente joven, nulípara, con un importante compromiso del abdomen inferior y destrucción de la cicatriz umbilical debido a un equivocado e injustificado procedimiento estético previo. Como cirujanos plásticos presentamos soluciones de acuerdo a las exigencias e insatisfacciones personales de nuestros pacientes. Nosotros respondemos a sus expectativas posibles y deseos factibles. En este caso específico, la expansión tisular fue proyectada para ser hecha en tiempos consecutivos con aprovechamiento y desplazamiento de los mismos expansores iniciales debido a la gran extensión, mediana y vertical, de la cicatriz.

En el segundo caso, la expansión tisular fue promovida por el aumento ponderal con expansión del tejido subcutáneo, que al ser lipoaspirado, permitió el avance del segmento dermograso. Me gustaría resaltar la metodología de anclaje de la fascia superficial del colgajo de avance sobre la fascia superficial del área cicatricial retirada como mecanismo de soporte a la tracción natural del colgajo en dirección a su posición original.
En el tercer caso, la paciente había sido sometida previamente a una abdominoplastia reversa con errónea bipartición del tejido graso. Logramos obtener 2 colgajos dermograsos desepitelizados (RELAT flap - reverse lateral thoracodorsal flap) aprovechando la autonomización promovida por esa previa abdominoplastia reversa. En este caso conseguimos realizar una verdadera reconstrucción del contorno corporal anterior.

La ausencia de citación de los artículos y trabajos de Baroudi y Pollock reside en el hecho de que estos procedimientos figuran como métodos auxiliares de cierre en las diversas técnicas de abdominoplastia.

Las alteraciones músculo-aponeuróticas abdominales no fueron discutidas en este artículo, pues estos pacientes no presentaban alteraciones distinguibles, cuya corrección específica y directa fue mencionada por nosotros en publicaciones precedentes..$^{(1-3)}$

Bibliografía

1. Caldeira, A.M.L., Lucas A. Flacidez Músculo-Aponeurótica Abdominal Intensa. Su Tratamiento. Cir plást iberolatinoam 1998, 24(1): 9-15.

2. Caldeira, A.M.L., Carrion, K., Jaulis, J. Repair of the Severe Muscle Aponeurotic Abdominal Laxity with Allopastic Mesh in Aesthetic Abdominoplasty. Aesth Plast Surg, https://doi;org/10.1007/s00266-018-1101-6.2018.

3. Caldeira, A.M.C, Robles, M.B.M., Challenges in Abdominoplasty. En: J.M. Avelar (Ed.) New Concepts on Abdominoplasty and Further Applications, DOI 10.1007/978-3-319-278513_30.2016. 